\title{
Investigation of an Electrostatic Discharge Protective Biodegradable Packaging Foam in the Logistic Chain
}

\author{
Ákos MOJZES 1 , Barnabás TóTH ${ }^{1}$ and Péter CSAVAJDA ${ }^{1}$ \\ I Széchenyi István University, Department of Logistics and Forwarding
}

\begin{abstract}
Since the beginning of the 20th century, logistics has undergone a huge technological development, which has, however, resulted in many negative effects as well. The industry, particularly in the packaging industry has been a massive waste producer, although recently it has forced the use of new materials and it started to focus on environmentally friendly technologies. During the transportation of finished and semi-finished Electrostatic Discharge (ESD) sensitive products, the product packaging system has a vital role. These kind of packaging materials must be suitable to both logistic (protection against mechanical and environmental stresses) and special ESD protection requirements. During the transportation of printed-circuit electronic products, ESD defense is then of primary significance. However there is a huge disadvantage for the use of various shield bags. Namely, this kind of associated packaging is particularly pollutant, it causes a lot of inconvenience in the form of waste. In order to rule out these materials from the packaging system, new innovative solutions have to be found. The investigated TPS (thermoplastic starch biodegradable foam) is subjected to a validation, a long process to certify that this material unites properties of two types of packaging materials at the same time. On the one hand, this packaging foam has to meet the requirements product defense. On the other hand, the material must be anti-static under the logistic stress effects. In case it is found suitable, it can be an alternative of the conventional materials. In this article, we investigate the ESD characteristic of TPS foam. As this material sensitive for environmental parameters during transportation, we make the relevant Surface Resistance ( $R_{s}$ ) tests on different temperature and humidity conditions. Based on result, the decision of the application can be done, as an ESD packaging material.
\end{abstract}

Key words - Eco-friendly, Biodegradable, TPS foam, ESD protection

\section{INTRODUCTION}

Packaging is the largest and most rapidly growing category of waste sector. In 2011, 79.9 million tonnes of waste was produced by the EU-27 states. Nearly $20 \%$ of the produced waste was plastic [1].

There are growing efforts to reduce its amount. Many researcher have focused on developing structural materials which could reduce the environmental impact of packaging [2], [3]. The Environmental Degradable Plastics (EDP) material's expansions are increasing in the packaging industry [4]. There are several areas of application, such as the food-stuff industry, as insulation material, as cushioning materials, in the pharmaceutical industry and as packaging of electrostatically sensitive products [5], [6], [7], [8], [9], [10].

Our paper's main thrust deals with electrostatically sensitive packaging.

\section{A. Importance of ESD protection}

The static electricity can pose a serious threat to electronic products during manufacturing, packaging and transportation. Electrostatic discharge is liable to lead to significant quality problems in the product, and detecting and repairing these problems afterwards may be remarkably costly. [11]

The adverse electric tension derives from the friction of materials, since the interfacial separation of charged materials may result in charge separation [12]. This phenomenon might occur for instance even while lifting the product off a traditional desktop or if the person handling the vulnerable parts of the product is standing up from their chair. Electrostatic discharge (ESD) is the most common type of discharge occurring due to friction.

There are many regulations and standards dealing with ESD protection, for example: ISO (ISO 10605:2008), ASTM (ASTM E1549-06), ANSI (ANSI/ESD S541-2008), IEC 61340-5-1 [13], [14], [15], [16].

According to the ANSI/ESD S541-2008 standard, we can separate the following three types of materials by their resistance material property: 
- Resistance of Dissipative Materials: these materials have a surface resistance (Ohm- $\Omega$ ) of greater than or equal to $1.0 \times 10^{4} \Omega$ but less than $1.0 \times 10^{11} \Omega$, or a volume resistance of greater than or equal to $1.0 \times 10^{4} \Omega$ but less than $1.0 \times 10^{11} \Omega$;

- Resistance of Conductive Materials: this kind of materials have a surface resistance of less than $1.0 \times 10^{4} \Omega$. Volume conductive materials have a volume resistance of less than $1.0 \times 10^{4} \Omega$;

- Resistance of Insulative Materials: an insulative material has a surface resistance $(\Omega)$ of greater than or equal to $1.0 \times 10^{11} \Omega$.

The appearance of electronic products (at the beginning of the spread) has not paid sufficient attention to the ESD. It is resulting damages under the logistic chain [17]. According to some sources the rudimentary ESD protections problems take the $5 \%$ of the whole market sales in the USA [18].

Nowdays the problems with it not as serious as in the early years because of the developed antistatic and shielding packagings. However the use of EDP instead of traditional plastics are increasing. Because these materials as cushioning or as insulating compared to traditional plastics can behave differently, so need to be closer examinated the protection against ESD [7], [8]. There is the describtion of the TPS foam investigation in the next chapter.

\section{MATERIAL AND TEST METHOD}

\section{A. Material}

Thermoplastic Starch (TPS) (Figure 1.) is a relatively new material for application as a biodegradable plastic and it is one of the main polymers studied today in this field. It is used alone or compounded, usually with polar synthetic polymers, in contents that usually exceed $50 \%$.

Starch is not a true thermoplastic but in the presence of plasticizers, (water, glycerin, sorbitol, etc.) at high temperatures $\left(90-180^{\circ} \mathrm{C}\right)$ and under shear, it readily melts and flows, allowing for its use as an injection, extrusion or blow molding material, similar to most conventional synthetic thermoplastic polymers. Thermoplastic starch has two main disadvantages when compared to most plastics currently in use, i.e. it is mostly water-soluble and in some climatic conditions it could have poor mechanical properties. [19]

During the production of TPS coiled starch totes are manufactured and cut the required size with a cutting machine.

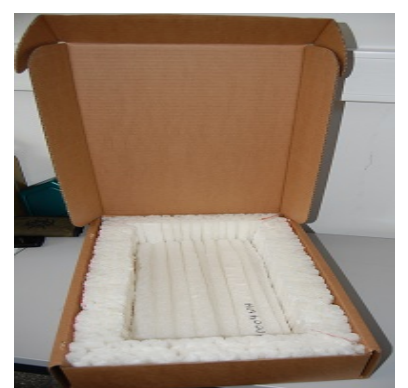

Figure 1: The TPS foam

Source: Own photo

To clearly see the difference between various types of ESD protection packaging devices and materials (Figure 1), the following table presents the different categories of consideration. The rating of each materials is based on an assessment (1-very unfavourable; 5-very favourable), whose values were based on relevant literatures and laboratory experiences. (see Table 1)

Table 1: Comparing the packaging solutions

\begin{tabular}{|c|c|c|c|c|c|}
\hline $\begin{array}{c}\text { Packaging } \\
\text { solution }\end{array}$ & Supply & Logistic & Manufacturing & Waste & $\begin{array}{c}\text { ESD } \\
\text { protecting }\end{array}$ \\
\hline $\begin{array}{c}\text { Shielding } \\
\text { bags }\end{array}$ & 2 & 4 & 4 & 1 & 5 \\
\hline
\end{tabular}


Logistics \& Sustainable Transport

Vol. 5, No. 1, November 2014, 25-33

doi: 10.1515/jlst-2015-0004

\begin{tabular}{|c|c|c|c|c|c|}
\hline EPS foam & 3 & 2 & 4 & 1 & 5 \\
\hline CFB $^{2}$ & 3 & 4 & 3 & 3 & 5 \\
\hline TPS foam & 2 & 3 & 3 & 5 & 5 \\
\hline
\end{tabular}

Source: [20], [21]

Note:

The mentioned categories include the following details:

- Supply: includes purchase details;

- Logistic: includes transportation, storage and handlings;

- Manufacturing: includes aspects of product manufacturing;

- Waste: includes all environmental aspects (recycling, reuse, biodegradability);

- ESD protecting: includes the protection ability against ESD.

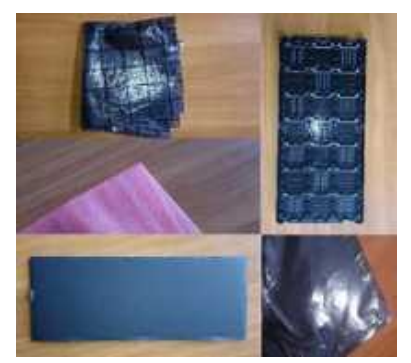

Figure 2: Ordinary ESD packaging solutions (shielding bag, EPS foam, CFB, antistatic foam)

Source: Own photo

As visible from the data above, TPS foam is completely environmentally friendly, and meets biodegradation requirements established by EN 13432 and ASTM D-6400 [22], [23].

In addition, it is strong and flexible, suitable for use both a single and multiple times. The environmental and mechanical characteristics of this material have been investigated and published by several authors [8], [24].

\section{B. Test method}

These tests are performed at $24{ }^{\circ} \mathrm{C}$ under standard conditions, but these ordinary tests do not show the real ESD function of the material. However, temperature and relative humidity can widely fluctuate in the logistic chain. Therefore, the required tests must be carried out in these conditions. The test must be conducted on with every levels of temperature and relative humidity, on sensitive (TPS, paper) and insensitive (EPS and other polyethylene derivatives) materials likewise.

During the test, we measured the surface resistance with a METRISO 2000 type meter. We used a climate chamber to simulate various levels of relative humidity and temperature (Figure 3). Measurements and the changing of conditions were carried out every 24 hours [25].

\footnotetext{
1 EPS: Expanded polystyrene foam with antistatic properties

2 CFB: Corrugated Fibre Board sheets/boxes with antistatic properties
} 


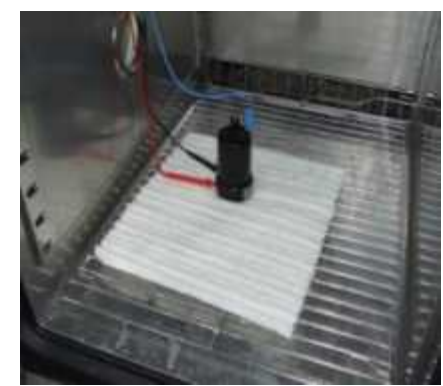

Figure 3: Parts of the surface resistance meter Source: Own photo

Surface resistance testing may be the most important test in evaluating materials. In the insulative range, materials become nonconductive and may hold static charges for several seconds or more. Often, the surface resistance of antistatic materials rises and falls when relative humidity fluctuates. $1.0 \times 10^{11} \Omega$ is the standard cut off for retention of static dissipative properties. In practice, however a lower cut-off is often desired for packaging materials because dry air may be encountered in shipping and handling. As opposed to this, relative humidity may reach $65 \%$ or even higher in warm and wet climatic conditions. Our measurements were so designed as to simulate both extremes and the conditions in between.

\section{ESD test of the TPS foam under various conditions}

This section introduces the examination of the TPS foam, an innovative type of packaging material, with the illustration of an ESD testing methodology.

The measurements were conducted first on normal constant temperature $\left(24^{\circ} \mathrm{C}\right)$ and on different levels of relative humidity (24-85\%). Then the material was investigated at higher temperatures. The results are presented in the following sections in chapter III[26]:

A. On $24{ }^{\circ} \mathrm{C}$ normal temperature and different relative humidity 24 to $85 \%$

B. On $35^{\circ} \mathrm{C}$ and 24 to $85 \%$ relative humidity

C. On $45^{\circ} \mathrm{C}$ and 24 to $85 \%$ relative humidity

\section{THE RESULt OF the EXAMINATIONS}

A. On $24{ }^{\circ} \mathrm{C}$ normal temperature and different relative humidity 24 to $85 \%$

The first examination was made on $24^{\circ} \mathrm{C}$, which was a fixed temperature. We investigated what kind of decrease can be observed the levels of ESD protection when relative humidity changes. At each part of the examination, We carried out three tests on the material. The following figures indicate the average results.

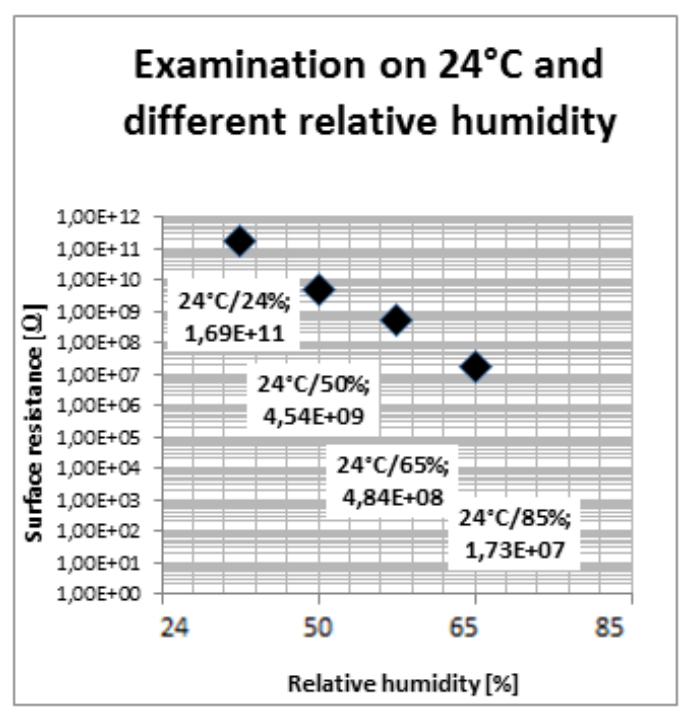


Logistics \& Sustainable Transport

Vol. 5, No. 1, November 2014, 25-33

doi: 10.1515/jlst-2015-0004

Figure 4: Average results of the test

Source: Own measurements and editing

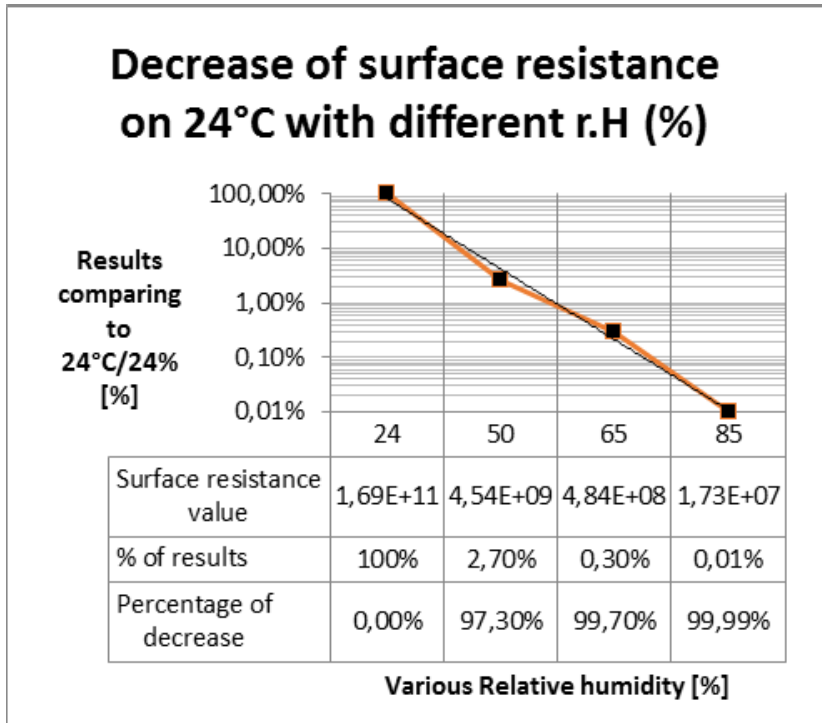

Figure 5: Decrease in surface resistance compare to the prescribed parameter Source: Own measurements and editing

The TPS foam has showed sharply decreasing surface resistance on higher r.H. The critical point is between $65 \%$ and $85 \%$ (see Figure $4-5$ ).

B. On $35^{\circ} \mathrm{C}$ and 24 to $85 \%$ relative humidity

In this section the temperature was $35^{\circ} \mathrm{C}$. The decrease of the surface resistance is shown in the following Figures 6-7. It is compared to the first examination $\left(24^{\circ} \mathrm{C}\right)$ and it can be observed that the loss of surface resistance is much greater (see Figure 7).

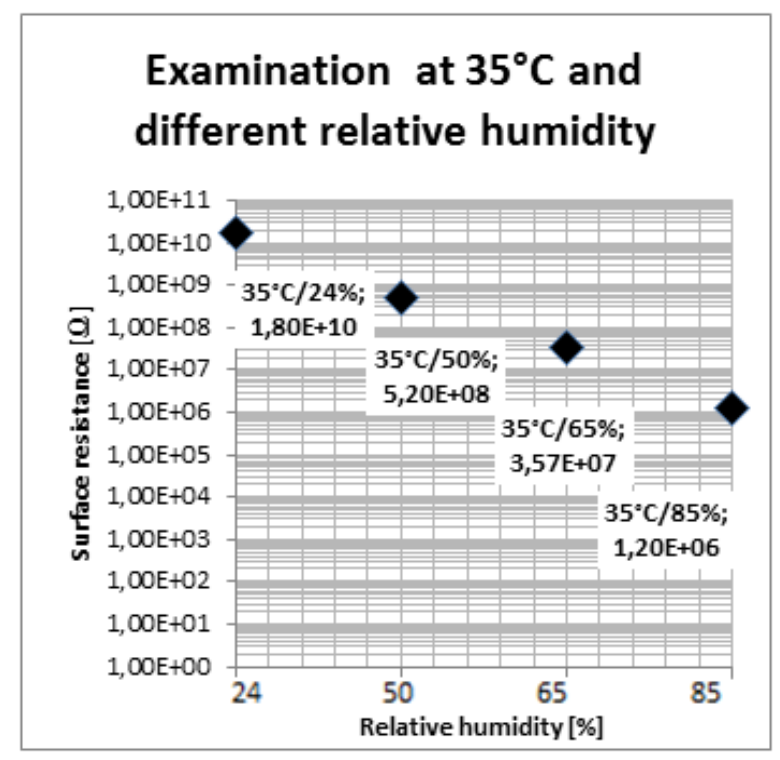

Figure 6: Avarage results of the test Source: Own measurements and editing 


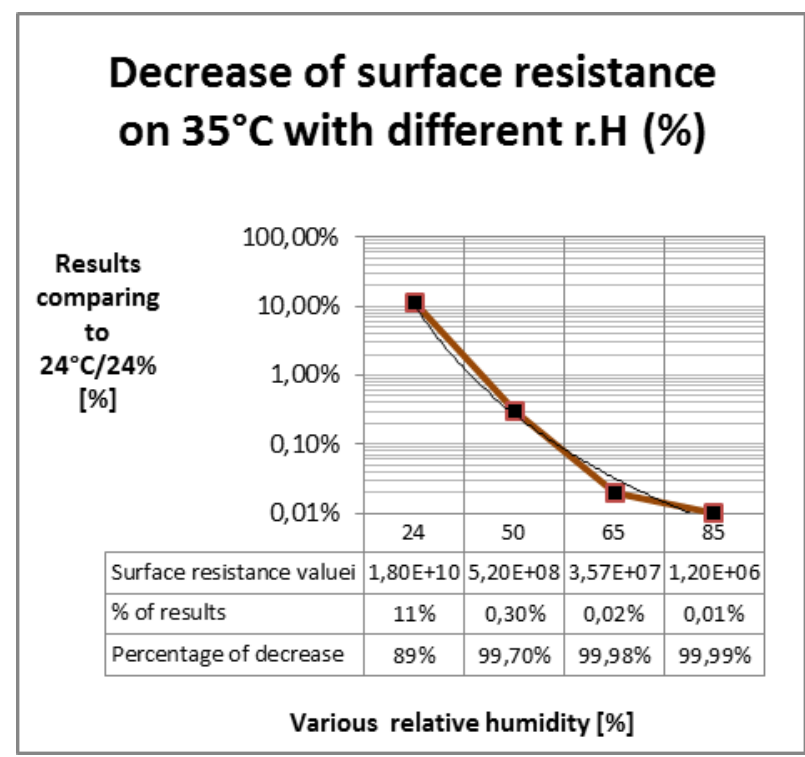

Figure 7: Decrease in surface resistance compare to the prescribed parameter Source: Own measurements and editing

C. The results on $45^{\circ} \mathrm{C}$ and 24 to $85 \%$ relative humidity

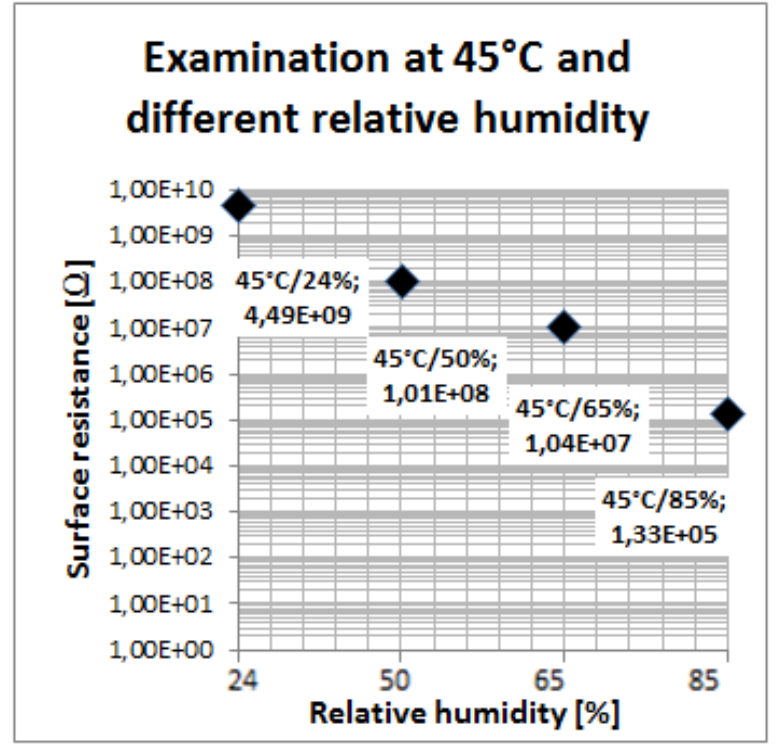

Figure 8: Avarage results of the test Source: Own measurements and editing 
Vol. 5, No. 1, November 2014, 25-33

doi: 10.1515/jlst-2015-0004

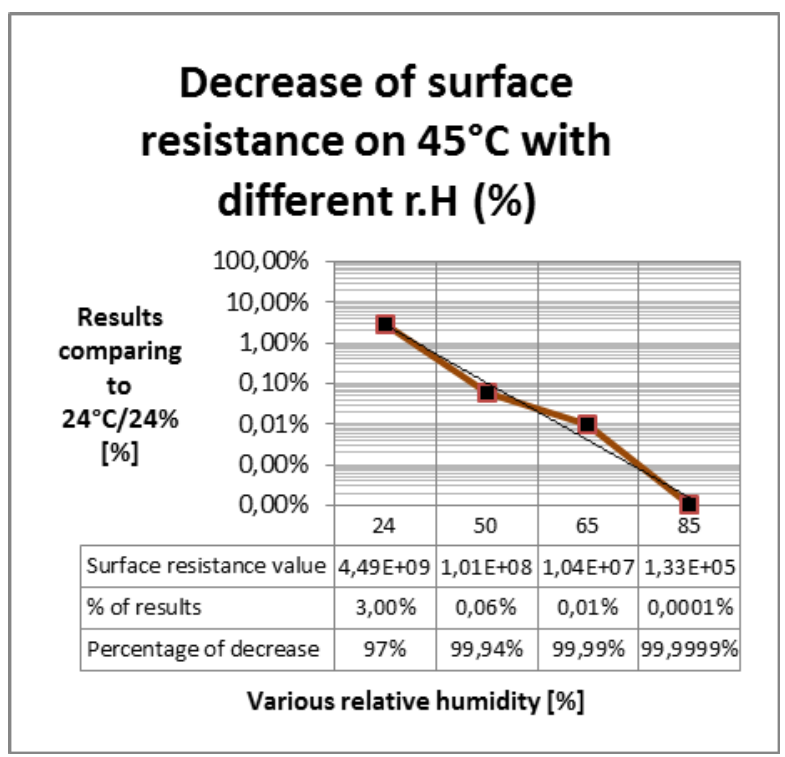

Figure 9: Decrease in surface resistance compare to the prescribed parameter Source: Own measurements and editing

At $45^{\circ} \mathrm{C}$ surface resistance continued to decrease below the value of the conductor's surface resistance. The largest decrease was perceived at $45^{\circ} \mathrm{C}$ and $85 \%$ r.H (see Figures 8-9).

\section{Summary of results}

At room temperature $\left(24^{\circ} \mathrm{C}\right)$, TPS foam performs well at all r.H levels, however, on $24^{\circ} \mathrm{C}$ and $85 \%$ r.H some unexpected fluctuation was observed. This is a really extreme environment and practically it is impossible to expose an ESD sensitive product to it, because of the multi-layer packaging (i.e. inner-outer packaging) [15].

However, due to the unexpected results at high humidity, additional measurements were required to investigate how the foam behaves. At the second and third round of the examinations the temperature was raised while using the previously defined r.H ranges.

The tests found that temperature changes are a negligible factor in the fluctuation, which is visible from the following table (see Table 10.). The critical point of this material is between $65 \%$ and 85\% r.H because TPS is made out of a natural composition, which, accordingly, has a great absorbency.

All this means that the material can be used with only some limitations on temperature and relative humidity. These limitations include that the material must be stored and used on a level of the humidity between $24 \%$ and $85 \%$. Otherwise, the foam can even become conductive at $85 \%$ humidity and at high level of temperature. The table below shows the connection between temperature and relative humidity and the level of ESD protection of TPS foam (Figure 10): 


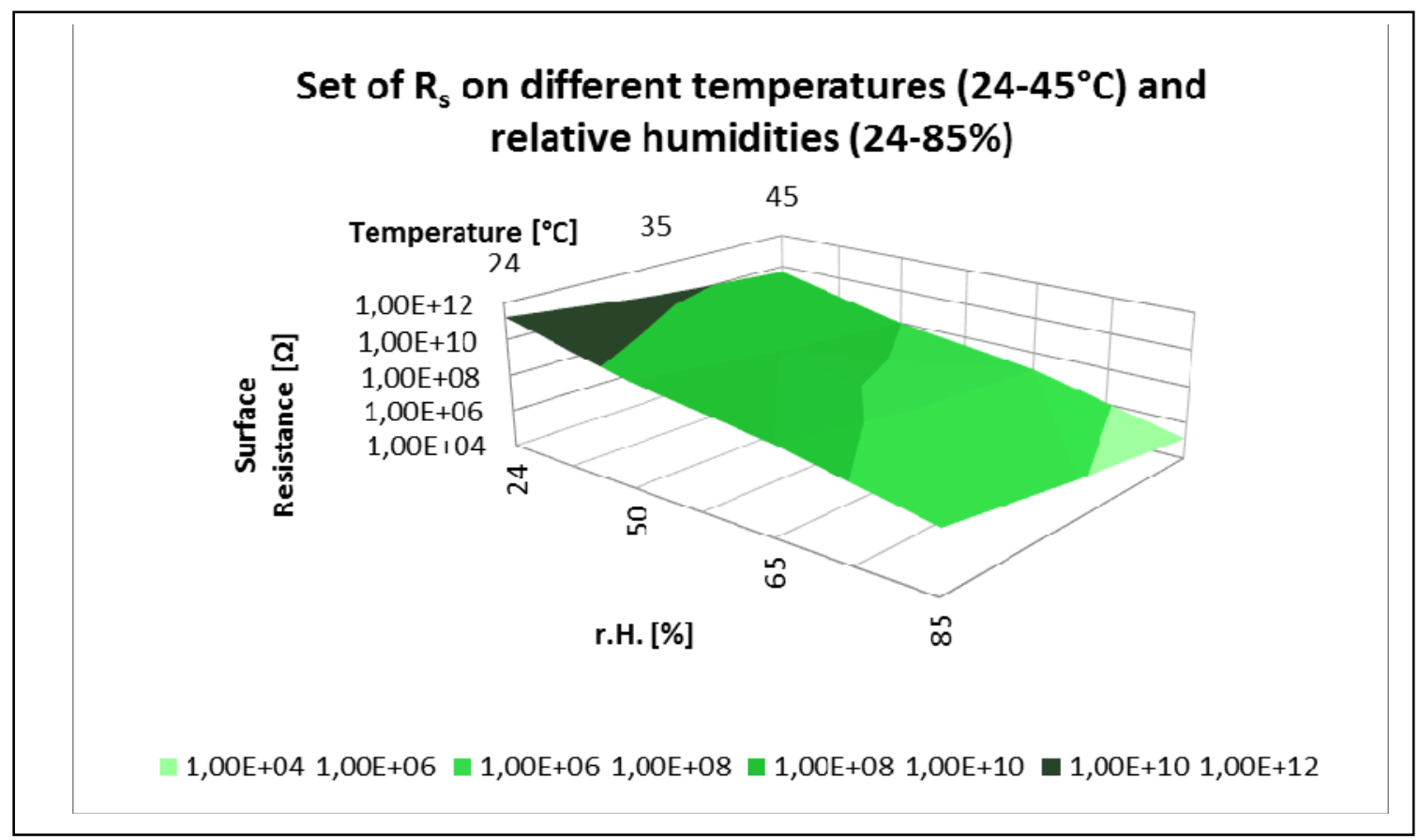

Figure 10: Set of Rs on different temperatures and relative humidities Source: Own measurements and editing

\section{CONCLUSION}

It has been proved that TPS foam is sensitive to high levels of relative humidity, which can adversely affect its utility as a packaging material. These influencing factors are liable to degrade the structural properties of the material including both mechanical protection and ESD protection.

The examination proved, that TPS foam suffers some minimal structural changes when it comes into contact with high levels of relative humidity, but it do not loses from its antistatic property, the material's surface resistance remains in antistatic range (between $1 \times 10^{5} \Omega$ and $1 \times 10^{11} \Omega$ ) as well. It is interesting that the change of temperature on a specific relative humidity only results small differences in surface resistance too.

In this examination, TPS foam met the established requirements as a packaging system of ESD sensitive products. Consequently, the foam can be suitable for intercontinental transportation in case the circumstances are guaranteed. It is determined, that this kind of environmentally friendly ESD protective packaging is useable where relative humidity and the temperature are controlled even by basic input. On the other hand, TPS foam can easily be used in container shipping, where as an inner (cushioning) packaging, there is no extreme temperature or relative humidity. We would like to propose this new packaging material for use because it has a great perspective in consumption. Today sustainable development is crucial for both producers and consumers. TPS foam is a modern and innovative material which has a lot of advantages against EPS foam, for instance it is particularly environmentally friendly and easy to reuse or recycle. With this material it is easy to reduce our biological footprint, and the disadvantages of TPS can easily be cancelled by a minimal amount of costs and efforts.

\section{REFERENCES}

1. EUROSTAT (2013): Packaging waste statistics. Found on 14th November 2014 on the webpage: http://epp.eurostat.ec.europa.eu/statistics_explained/index.php/packaging_waste_statistics

2. Song J. H., et. al. (2009): Biodegradable and compostable alternatives to conventional plastics, Philosophical Transactions of The Royal Society B, 2009 (364), 2127-2139

3. Kyrkou, I., Briassoulis D. (2007): Biodegradation of agricultural plastic films: a critical review, Journal of Polym Environ, 2007 (15), 125-150

4. Krzan, A., et. al. (2006): Standardization and certification int he area of environmentally degradable plastics, Polymer Degradation and Stability, 2006 (91), 2819-2833

5. Siracusa, V. (2008): Biodegradable polymers for food packaging: a review. Trends in Food Science \& Technology Volume 19, Issue 12, December 2008, 634-643 
6. Haugaard, V.K., et. al. (2001): Potentional Food applications of Biobased Materials, An EU concerned Action Project, Weinhein, 182- 200

7. Butschli, J. (2007): Evaluation of a biodegradable foam for protective packaging applications, Journal of Packaging Technology and Science Volume 20, Issue 6, 413-419, November/December 2007

8. Mojzes, Á, Böröcz, P. (2011): Possible method to define cushion characteristic on new type of environmental friendly foam, In: H Bartolo (editor), SIM 2011 Proceedings of Sustainable Intelligent Manufacturing, Lisbon: IST Press, 2011 . 525-532.

9. Kumar, S., Gupta, S.K. (2012): Applications of Biodegradable Pharmaceutical Packaging Materials: A Review. Middle-East Journal of Scientific Research 12 (5): 699-706, 2012 ISSN 1990-9233

10. Azlan, M.; David, N.V. (2011): Biodegradable material options for industrial and goods packaging Humanities, Science and Engineering (CHUSER), 2011 IEEE Colloquium on , vol., no., 23-27, 5-6 Dec. 2011

11. Narkis, M., et. al. (1998): New Injection Moldable ESD Compounds Based on Very Low Carbon Black Loadings, Electrical Overstress/Electrostatic Discharge Symposium Proceedings, 98.1-98.10

12. Kit L. Yam, et al. (2009): The Wiley Encyclopedia of Packaging Technology, Third Edition, John Wiley \& Sons , ISBN 978-0-470-08704-6, 389

13. International Organization for Standardization: Road vehicles -- Test methods for electrical disturbances from electrostatic discharge, Switzerland

14. ASTM: Standard Specification for ESD Controlled Garments Required in Cleanrooms and Controlled Environments for Spacecraft for Non-Hazardous and Hazardous Operations, West Conshohocken, PA, USA

15. American National Standards Institute: Packaging Materials for ESD Sensitive Items, Washington, DC, USA

16. International Electrotechnical Commission: Electrostatics - Part 5-1: Protection of electronic devices from electrostatic phenomena - General requirements, Switzerland

17. Singh, S. P., H. El-Khateeb (1994): Evaluation of a Proposed Test Method to Measure Surface and Volume Resistance of Static Dissipative Packaging Materials, Journal of Packaging Technology and Science, Volume 7, Issue 6, pages 283-289, November/December 1994

18. T., Trost (1995): Electrostatic discharge (ESD)-Facts and faults-A review, Journal of Packaging Technology and Science, Volume 8, Issue 5, pages 231-247, September/October 1995

19. Curvelo, A. et. al. (2001): Thermoplastic starch cellulosic fiber composites: preliminary results, Carbohydrate Polymers. Barking. Volume 45, 183-188, 2001

20. Narayan, R. (2005): Plastics from Renewable Resources, Global Plastics Environmental Conference (GPEC 2005): Creating Sustainability for the Environment, Paper 29

21. Morrissey, A.J, Browne, J., (2004): Waste management models and their application to sustainable waste management Waste Management, Volume 24, Issue 3, 297-308, 2004

22. Biodegradable Products Institute: Proof of compostability of plastic products, New York, USA

23. ASTM: Standard Specification for Labeling of Plastics Designed to be Aerobically Composted in Municipal or Industrial Facilities, West Conshohocken, PA, USA

24. Narayan, R. (1998): Commercialization of Technology: "A Case Study of Starch Based Biodegradable Plastics" In: Paradigm for Successful Utilization of Renewable Resources, Eds: D.J. Sessa and J.L. Willett, AOCS Press, Champaign, Illinois, pp. 78, 1998.

25. Nabar, Y., et. al. (2006): Twin-Screw Extrusion Production and Characterization of Starch Foam Products for Use in Cushioning and Insulation Applications, Polymer Engineering and Science. 2006;46(4), 438-451

26. Paasi, J., (2001): Performance of ESD protective materials at low relative humidity, Journal of Electrostatics, Volumes 51-52, May 2001, 429-434

\section{AUTHORS}

Ákos Mojzes, is a research fellow at Széchenyi István University, Department of Logistics and Forwarding, Győr 9026 Hungary (email: mojzesa@sze.hu).

Barnabás Tóth is a student at the Széchenyi István University, Department of Logistics and Forwarding, Győr 9026 Hungary (email:brown.toth@ gmail.com).

Péter Csavajda is a student at the Széchenyi István University, Department of Logistics and Forwarding, Györ 9026 (email: petercsavajda@gmail.com). 